\title{
First report of occurrence of Candidatus Phytoplasma trifolii-related strain causing witches' broom disease of chilli in India
}

\author{
Ashutosh Rao $^{1} \cdot$ Sonia Goel $^{1} \cdot{\text { Manish } \operatorname{Kumar}^{1} \cdot \text { Gopala }^{1} \text { - G. P. Rao }}^{1}$
}

Received: 1 April 2017 / Accepted: 23 May 2017 / Published online: 20 June 2017

(C) Australasian Plant Pathology Society Inc. 2017

\begin{abstract}
During February 2017, 20\% of the chilli plants in fields at the Indian Agricultural Research Institute, New Delhi, India showed witches' broom symptoms of suspected phytoplasma etiology. Phytoplasma association was confirmed by utilizing a nested PCR assay with universal primer pairs $\mathrm{P} 1 / \mathrm{P} 7$ and $3 \mathrm{~F} / 3 \mathrm{R}$ that target the phytoplasma $16 \mathrm{~S} r R N A$ gene. The chilli witches' broom phytoplasma (CWBP) sequence (Acc. No. KY612251) shared 100\% nucleotide sequence identity with the 16S rDNA sequences of identified strains of 'Candidatus Phytoplasma trifolii' subgroup D (16SrVI-D) phytoplasmas associated with Lens culinaris' witches'-broom (Acc. No. KY439869), brinjal little leaf (Acc. No. KX284698), Brassica oleracea var. capitata witches' broom (Acc. No. KX671553) and Apium graveolens white leaf (Acc. No. KX671551) in pair wise sequence comparisons. The CWBP strain also clustered with strains of 'Candidatus Phytoplasma trifolii' subgroup D in phylogenetic comparison analysis. This is the first report of association of 'Ca. P. trifolii' subgroup D with witches' broom disease of chilli in India.
\end{abstract}

Keywords Phytoplasma $\cdot$ Identifiation $\cdot$ Chilli $\cdot$ India

Chilli (Capsicum annum, fam: Solanaceae) is one of the most valuable spice crops of India and is grown largely for its fruits all over India. It is also used for vegetables, spices, condiments, sauces and pickles. India is the largest producer, consumer and exporter of chilli. Chilli is grown in 0.17 million

G. P. Rao

gprao_gor@rediffmail.com

1 Division of Plant Pathology, IARI (Indian Agricultural Research Institute), Pusa Campus, New Delhi 110012, India hectares with production of 1.98 million tonnes (Anonymous 2015). Major factors that limit chilli production besides its narrow genetic base are extreme susceptibility to biotic and abiotic stresses. Phytoplasmas are non-culturable prokaryotic microorganisms that cause several hundred diseases of various plants and are transmitted by phloem-feeding insects. Plants infected with phytoplasmas exhibit a variety of symptoms that suggest profound disturbances to the normal plant behaviour and physiology. Phytoplasma diseases are important worldwide, with a high economic impact on crop production and quality (Bertaccini et al. 2014). Chilli is affected by several diseases of which little leaf caused by phytoplasmas is one of the important factors causing considerable economic losses (Singh and Singh 2000). Limited information is available on phytoplasma infection of chilli crops in India. Hence, the present work included PCR screening for the presence of phytoplasmas, $16 S$ rRNA gene sequence comparison and phylogeny clustering based on the $16 \mathrm{~S} r R N A$ gene in samples collected from chilli and brinjal plants.

During a survey of experimental chilli fields at IARI, New Delhi in February 2017, an incidence of $20 \%$ of phytoplasma suspected symptoms of witches' broom and little leaf were observed in chilli plants (Fig. 1b). Besides chilli fields, little leaf symptoms were also observed in brinjal plants (Fig. 1d). Total genomic DNA from four symptomatic chilli plants (leaf veins and stem portions) and four symptomatic brinjal plants (leaf vein tissue) along with three symptomless samples of both chilli (Fig. 1a) and brinjal plants (Fig. 1c) were extracted following the procedure described by Ahrens and Seemuller (1992). The DNA concentration was determined spectrophotometrically and the quality evaluated by agarose gel electrophoresis. For the detection of phytoplasmas, nested PCR reactions were performed using primers $\mathrm{P} 1 / \mathrm{P} 7$ in the first round (Deng and Hiruki 1991), followed by the 3F/3R primer pair (Manimekalai et al. 2010). PCR reactions were performed in a 


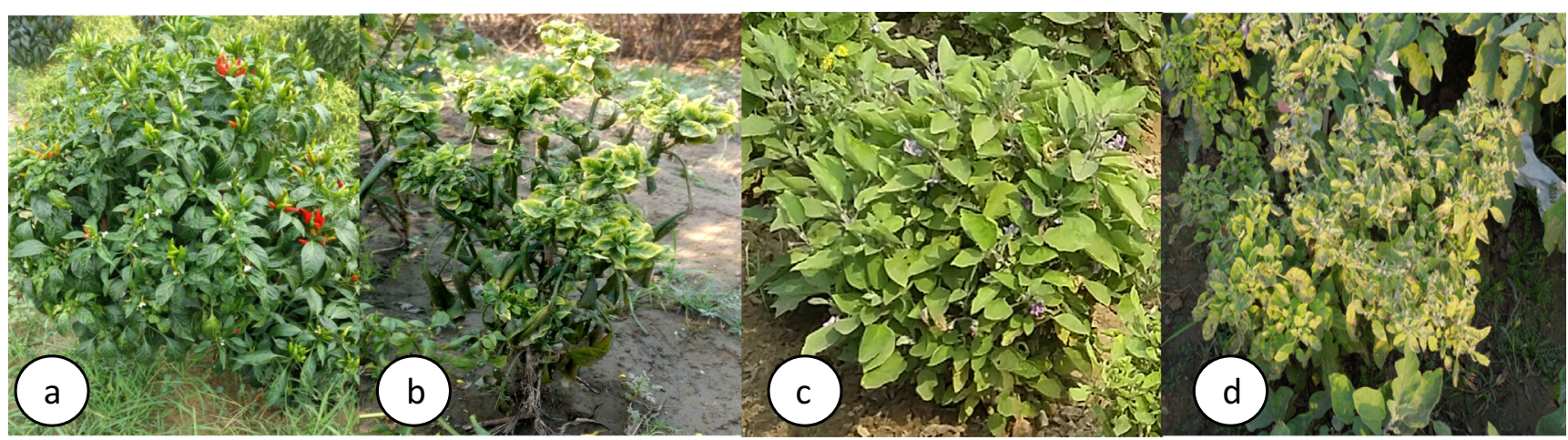

Fig. 1 a, Symptomless chilli plant b, Symptomatic chilli plant showing witches' broom and little leaf symptoms, c, Symptomless brinjal plant and d, Symptomatic brinjal plant showing little leaf symptoms

Mastercycler (Eppendorf, Germany) and the cycling protocol followed as described by Rao et al. (2014). The DNA isolated from Datura stramonium leaf tissue infected with witches' broom (16SrVI-D) was used as positive control. The PCR products $(5 \mu \mathrm{l})$ were analyzed by electrophoresis in $1 \%$ agarose gel in $1 \mathrm{X}$ TAE buffer, stained with good view dye, and visualized using a UV transilluminator. The amplified $16 \mathrm{~S}$ rDNA phytoplasma fragments were purified using the
Wizard $^{\mathrm{R}}$ SV Gel and PCR Clean-up System (Promega, Madison, USA).

PCR amplification with primer pair P1/P7 did not yield the expected $1.8 \mathrm{~kb}$ product of the $16 S \mathrm{rRNA}$ gene region from any of the symptomatic chilli and brinjal samples. However, $1.3 \mathrm{~kb}$ DNA products were amplified from symptomatic chilli and brinjal plants and the positive control of $D$. stramonium by using the $3 \mathrm{~F} / 3 \mathrm{R}$ primer pair, in nested PCR. No
Fig. 2 Phylogenetic tree constructed by neighbor-joining method showing the relationships between CWBP, BLL phytoplasma and the reference phytoplasma strains. Accession numbers are specified in the tree. Acholeplasma laidlawii was used as the outgroup. Mega 6.0 software was used to construct the tree. Numbers on branches are bootstrap values obtained for 1000 replicates

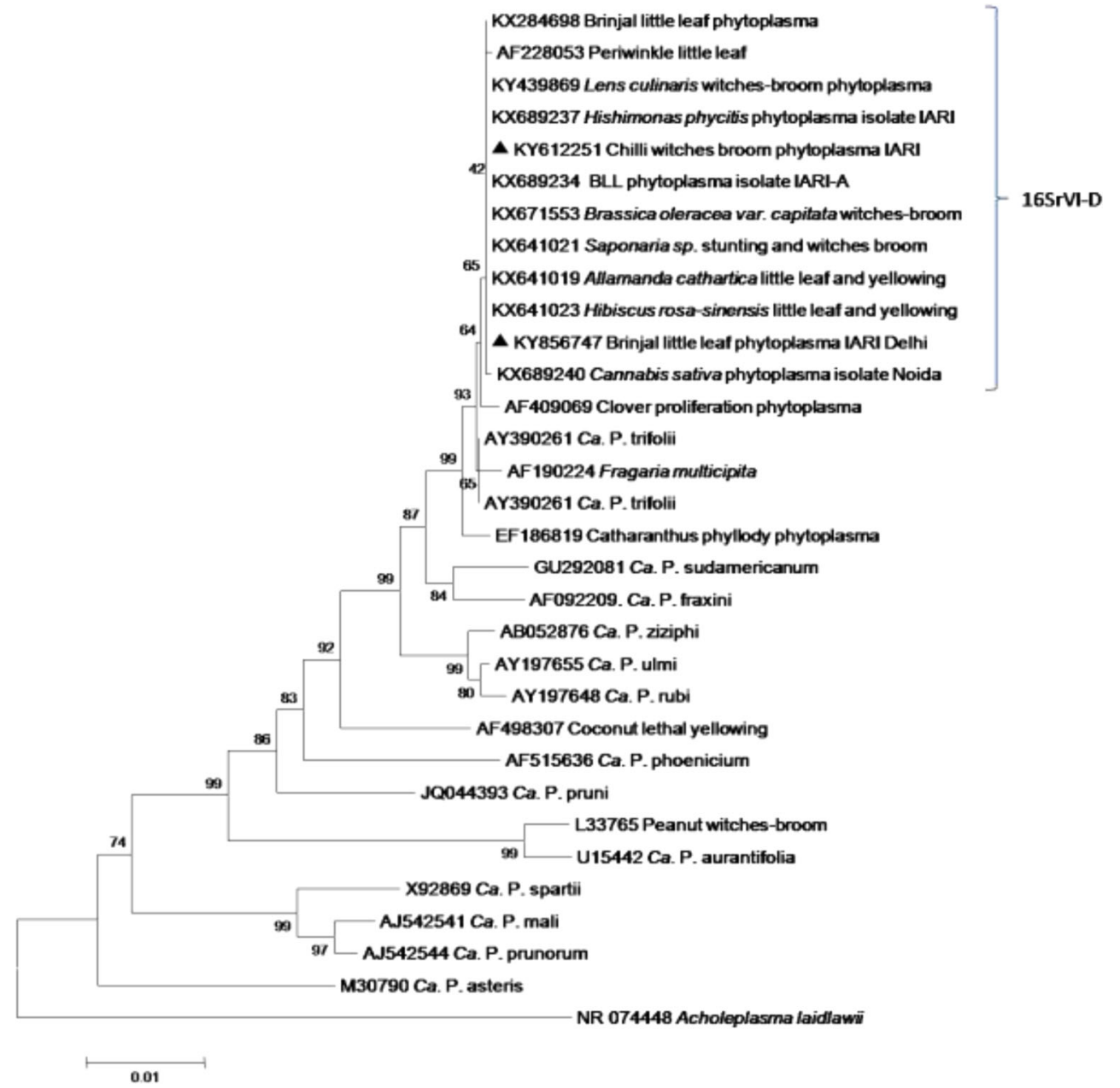


amplifications were observed in any of the symptomless chilli and brinjal samples. All of the four amplicons obtained with the $3 \mathrm{~F} / 3 \mathrm{R}$ primers from symptomatic samples of chilli and brinjal were purified and sequenced bi-directionally. The 16S rDNA sequences were assembled and analysed using the BLAST and Bioedit programs (http://www.mbio.ncsu. edu/bioedit/bioedit.html). The representative sequences of phytoplasmas from chilli and brinjal in the present study were submitted to GenBank with Acc. No. KY612251 (chilli) and KY856747 (brinjal). BLAST comparison revealed that the phytoplasma identified in chilli and brinjal exhibited over $99 \%$ sequence identity of its $16 \mathrm{~S} \mathrm{rDNA}$ sequence with those of ' $\mathrm{Ca}$. P. trifolii' and related strains and $100 \%$ sequence identity with Lens culinaris witches' broom (Acc. No. KY439869), brinjal little leaf (Acc. No. KX284698), Brassica oleracea var. capitata witches' broom (Acc. No. KX671553) and Apium graveolens white leaf (Acc. No. KX671551). The phylogenetic tree was constructed using $16 \mathrm{~S}$ rDNA sequences belonging to phytoplasmas classified into distinct groups, the sequences of strains representative of the subgroups that constitute the 16SrVI group and the sequences of strains of chilli and brinjal under study, using MEGA6 software (Tamura et al. 2013) using the neighbour-joining method with default values and 1000 replicates for boostrap sanalysis. Acholeplasma laidlawii 16S rDNA sequence (Acc. No. NR074448) was used as the outgroup to root the phylogenetic tree. The phylogenetic tree based on the $16 \mathrm{~S}$ rDNA sequences supported the BLAST sequence comparison results (Fig. 2). The chilli and brinjal phytoplasma was grouped in the same phytoplasma cluster of ' $\mathrm{Ca}$. P. trifolii' subgroup D. 'Candidatus P. trifolii' has been reported to infect various vegetables, ornamentals and weeds in India and abroad (Bertaccini et al., 2014). Earlier, different phytoplasma strains were identified and characterized associated with chilli plants in different countries like India ('Ca. P. asteris', 16SrII-D; Khan and Raj 2006; Sharma et al. 2015) and Indonesia (' $\mathrm{Ca}$. P. aurantifolia', Harling et al. 2009), China (16SrI-B; Li et al. 2013), New Mexico ('Ca P. asteris', 'Ca P. trifolii'; Randall et al. 2009; Santos-Cervantes et al. 2008), Russia (16SrXII-A; Ember et al. 2011), Iran (' $\mathrm{Ca}$. P. aurantifolia'; Faghihi et al. 2016), Australia (16SrII; TranNguyen et al. 2003) and Spain ('Ca. P. trifolii'; Castro and Romero, 2002). In the present study, we confirmed association of 'Ca. P. trifolii' subgroup D of phytoplasmas with chilli and brinjal plants at IARI, New Delhi, India. In India, ' $C a$. P. trifolii' subgroup D phytoplasmas have been reported to be associated with several diseases of plants, viz. sesame, Hibiscus rosasinensis, Saponaria officinalis, Allamanda cathartica and brinjal (Madhupriya et al. 2015; Khasa et al. 2016; Kumar et al. 2017). In addition, many weed species including Datura stramonium, Portulaca oleracea and Cannabis sativa subsp. sativa have also been reported to be alternate hosts of the 16SrVI-D subgroup of phytoplasmas in India (Rao and Kumar 2017). This new report of association of a 16SrVI-D subgroup of phytoplasma with witches' broom of chilli in India is important because of its epidemioloical significance. The results indicate that this phytoplasma strain might cause significant yield losses to a wide range of crops, and because it can be transmitted by leafhopper vectors it poses a serious socio-economic threat to commercially grown chilli and other important agricultural crops in India.

Acknowledgements The authors are thankful to ICAR, New Delhi for providing Extramural Research funding and the Head, Division of Plants Pathology, IARI, New Delhi for providing laboratory facilities.

\section{References}

Ahrens U, Seemuller E (1992) Detection of DNA of plant pathogenic mycoplasma-like organisms by a polymerase chain reaction that amplifies a sequence of the 16S rRNA gene. J Phytopathol 82: $828-832$

Anonymous (2015) http://nhb.gov.in

Bertaccini A, Duduk B, Paltrinieri S, Contaldo N (2014) Phytoplasmas and phytoplasma diseases: a severe threat to agriculture. Am J Plant Sci 5(12):46-62

Castro S, Romero J (2002) The association of clover proliferation phytoplasma with stolbur disease of pepper in Spain. J Phytopathol 150(1):25-29

Deng S, Hiruki C (1991) Amplification of 16Sr RNA genes from culturable and non-culturable mollicutes. J Microbiol Methods 14: 53-61

Ember I, Acs Z, Munyaneza JE, Crosslin JM, Kolber M (2011) Survey and molecular detection of phytoplasmas associated with potato in Romania and southern Russia. Eur J Plant Pathol 130(3):367-377

Faghihi MM, Taghavi SM, Safaei A, Siampour M, Najafabadi SM (2016) First report of a phytoplasma associated with bell pepper big bud disease in Iran. New Dis Rep 33:15

Harling R, Arocha Y, Harju V, Tobing C, Boa E, Kelly P, Reeder R (2009) First report of 16SrII 'Candidatus Phytoplasma aurantifolia'infecting chilli and tamarillo in Indonesia. Plant Pathol 58(4):791

Khan MS, Raj SK (2006) First report of molecular detection of an Aster yellows phytoplasma ('Candidatus Phytoplasma asteris') isolate infecting chilli (Capsicum annuum) in India. Plant Pathol 55(6):822

Khasa E, Gopala TA, Prabha T, Rao GP (2016) Molecular characterization of phytoplasmas of 'Clover proliferation'group associated with three ornamental plant species in India. 3 Biotech 6(2):237

Kumar M, Priya M, Rao GP (2017) Molecular characterization, vector identification and sources of phytoplasmas associated with brinjal little leaf disease in India. 3 Biotech 7:7. doi:10.1007/s13205-0170616-x

Li ZN, Zhang L, Song JG, Wu YF (2013) Molecular detection and identification of phytoplasma associated with pepper witches' broom in China. Phytoparasitica 41(4):429-434

Madhupriya RGP, Kumar A, Baranwal VK (2015) Classification of the sesame phytoplasma strains in India at the $16 \mathrm{Sr}$ subgroup level. J Plant Pathol 97:523-528

Manimekalai R, Soumya VP, Kumar RS, Selvarajan R, Reddy K, Thomas GV, Sasikala M, Rajeev G, Baranwal VK (2010) Molecular detection of 16SrXI group phytoplasma associated with root (wilt) disease of coconut (Cocus nucifera) in India. Plant Dis 94:636

Randall JJ, Bosland PW, Hanson SF (2009) Brote grande, a new phytoplasma-associated disease of chile peppers. Plant Dis 93(9): 968 
Rao GP, Kumar M (2017) World status of phytoplasma diseases associated with eggplant. Crop Prot 96:22-29

Rao GP, Madhupriya TAK, Kumar S, Baranwal VK (2014) Identification of sugarcane grassy shoot-associated phytoplasma and one of its putative vectors in India. Phytoparasitica 42:349-354

Santos-Cervantes ME, Chávez-Medina JA, Mendez-Lozano J, LeyvaLopez NE (2008) Detection and molecular characterization of two little leaf phytoplasma strains associated with pepper and tomato diseases in Guanajuato and Sinaloa, Mexico. Plant Dis 92(7): $1007-1011$
Sharma A, Sharma S, Kang S (2015) First report of a new" Candidatus phytoplasma Australasia"-related strain in Capsicum annuum in India. J Plant Pathol 97(3):548

Singh D, Singh SJ (2000) Chilli little leaf - a new phytoplasma disease in India. Indian Phytopath 53(3):309-310

Tamura K, Stecher G, Peterson D, Filipski A, Kumar S (2013) MEGA6: molecular evolutionary genetics analysis, version 6.0. Mol Biol Evol 30:2725-2729

Tran-Nguyen LT, Persley DM, Gibb KS (2003) First report of phytoplasma disease in capsicum, celery and chicory in Queensland, Australia. Aus Plant Pathol 32(4):559-560 